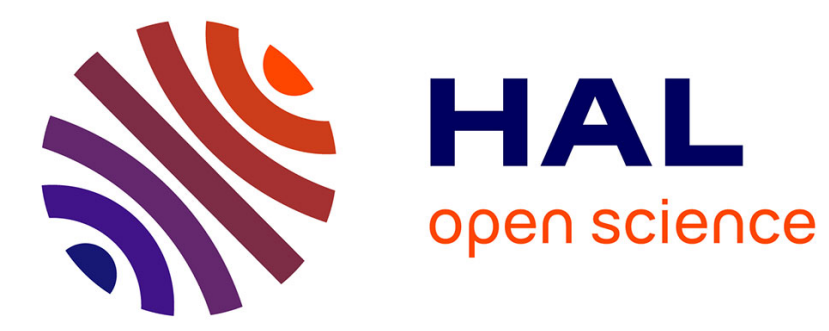

\title{
Saturation of the Kerr effect in carbon disulfide
}

Georges Boudebs, V. Besse, H. Leblond

\section{To cite this version:}

Georges Boudebs, V. Besse, H. Leblond. Saturation of the Kerr effect in carbon disulfide. Nonlinear Photonics, 2014, Barcelona, Spain. pp.NTh1A.1, 10.1364/NP.2014.NTh1A.1 . hal-02442906

\section{HAL Id: hal-02442906 https://hal.science/hal-02442906}

Submitted on 20 Jan 2020

HAL is a multi-disciplinary open access archive for the deposit and dissemination of scientific research documents, whether they are published or not. The documents may come from teaching and research institutions in France or abroad, or from public or private research centers.
L'archive ouverte pluridisciplinaire HAL, est destinée au dépôt et à la diffusion de documents scientifiques de niveau recherche, publiés ou non, émanant des établissements d'enseignement et de recherche français ou étrangers, des laboratoires publics ou privés. 


\title{
Saturation of the Kerr effect in carbon disulfide
}

\author{
G. Boudebs ${ }^{(*)}$, V. Besse, and H. Leblond \\ LUNAM Université, Université d'Angers, LPhiA, Laboratoire de Photoniques d'Angers, EA 4464, 49045 Angers Cedex 01, France \\ (*) Tel:(33) 2.41.73.54.26, Fax:(33) 2.41.73.52.16, email: georges.boudebs@univ-angers.fr
}

\begin{abstract}
Accurate measurements of the nonlinear index in carbon disulfide shows an unusual saturation law of the Kerr effect which can be used to built a model of light propagation describing the filamentation in this liquid.

OCIS Codes: (190.0190) Nonlinear optics; (190.3270) Kerr effect; (190.4720) Optical nonlinearities of condensed matter.
\end{abstract}

\section{Introduction}

Filamentation of a high intensity optical pulse was observed even before the concept of optical soliton was introduced [1]. The high intensities reached in filaments allow observing many nonlinear phenomena, such as high harmonic or supercontinuum generation [2]... Recently two-dimensional spatial soliton propagation essentially stabilized due to $\chi^{(3)}-\chi^{(5)}$ balance in carbon disulfide $\left(\mathrm{CS}_{2}\right)$ at $\lambda=920 \mathrm{~nm}$ was reported [3], naturally paving the way to light filamentation in this liquid. However, at both wavelengths 1064 and $532 \mathrm{~nm}$ the standard model for the description of nonlinear dynamics of a light beam in this medium, which is based on the cubic nonlinear Schrodinger (NLS) equation, eventually refined by adding several terms to account for higher order nonlinear coefficients, does not remain valid as an accurate description of the saturation of the Kerr effect. We report in this paper on accurate measurements of effective $n_{2}$ really encountered by the material versus increasing intensities. These measurements lead to an alternative model in filamentation when combined to NLS equation [4].

\section{Experiments: observation of the filamentation and nonlinear coefficient measurements}

First we investigate the propagation of a laser beam in a cell filled with $\mathrm{CS}_{2}$, with thickness $\mathrm{L}=10 \mathrm{~mm}$. The experimental setup is composed of a focusing lens $(f=20 \mathrm{~cm})$ into the entry of the cell and an imaging system ( $x 10$ magnification) that can be translated in order to image the entry and the output of the cell. The light source is an Nd: YAG laser, emitting at wavelength $\lambda=$ $532 \mathrm{~nm}, 12 \mathrm{ps}$ long pulses with Gaussian time profile, linearly polarized, operating at a repetition rate of $10 \mathrm{~Hz}$. The output beam is acquired using a CCD sensor triggered with the laser. Beam shaping is achieved using a spatial filter, so that the spatial profile of the collimated beam is close to Gaussian at the input of the setup. By adjusting the beam waist at the focus $\left(\omega_{0}=\sqrt{\lambda z_{R} / \pi}=13 \mu \mathrm{m}\right)$, we fixed $z_{R}$, the Rayleigh distance to be one tenth of L. Above an input energy per pulse of $1.4 \mu \mathrm{J}$, we observed the formation of filaments at the output of the cell. Changing the input intensity allows to increase the number of filaments (Fig 1-a).

To give a theoretical account of these observations, an accurate measurement of the nonlinear parameters of $\mathrm{CS}_{2}$ is required. We performed it using the well-known Z-scan method [5]. The standard model for the evolution of the light intensity I and the beam phase $\varphi$ during propagation in a nonlinear medium, in the thin sample approximation can be set as:

$$
\begin{gathered}
\frac{\mathrm{dI}}{\mathrm{dz}}=-\alpha \mathrm{I}-\beta \mathrm{I}^{2}-\gamma \mathrm{I}^{3}, \\
\frac{\mathrm{d} \varphi}{\mathrm{dz}}=\mathrm{kn}_{2, \mathrm{eff}} \mathrm{I}=\mathrm{k}\left(\mathrm{n}_{2} \mathrm{I}+\mathrm{n}_{4} \mathrm{I}^{2}\right),
\end{gathered}
$$

where $\mathrm{z}$ is the propagation direction, $\mathrm{k}$ the wave vector. $\alpha, \beta$ and $\gamma$ are the linear, two-photon, and three-photon absorption coefficients, $\mathrm{n}_{2}$ and $\mathrm{n}_{4}$ the third-order and fifth-order nonlinear refraction indices, respectively. Measurements using a nonlinear fitting of the curve yielded by numerical solution of the differential evolution equation and analytical solutions of equations (1) and (2), with the necessary approximations, have been given [6]. Eqs. (1) and (2) can be solved analytically in special cases where some of the nonlinear coefficients vanish [7]. In the general case, an analytical expression of $\mathrm{z}$ versus I is found and inverted numerically [8]. It is known that $\mathrm{CS}_{2}$ has neither linear nor two-photon absorption $(\alpha=0, \beta=0)$. Moreover, one of the absorption bands of $\mathrm{CS}_{2}$ is centred at about $200 \mathrm{~nm}$ (see figure 1(a) in [3]), which is approximately the third harmonic $\lambda / 3$ of the wavelength $\lambda=532 \mathrm{~nm}$. This closeness to resonance increases the fifth order optical susceptibility, $\left|\chi^{(5)}\right| \propto \gamma$. We used the recent D4 $\sigma-4$ f-Z-scan method [9], together with the numerical inversion related to the analytic solution of (1) and (2) (see [8] for details). The change in transmittance of the material is observed via a cooled CCD camera $\left(-30^{\circ} \mathrm{C}\right)$. For this, the used setup is a $4 \mathrm{f}$ system. A top-hat beam object is located in the front focal plane focus of the first lens, its Fourier transform is obtained in its rear focal plane, where is placed the sample, here a $1 \mathrm{~mm}$ thick cell filled with $\mathrm{CS}_{2}$. The same point is also the object plan of the 
second lens, which performs another Fourier transform into the CCD. A recent improvement of the technique allows to avoid the division of the two normalized Z-scan transmittances (closed and open aperture ones) by recording the beam waist relative variations according to the second order momentum. We measured the effective third-order refraction index $\mathrm{n}_{2, \text { eff }}$ with increasing intensity, for two wavelengths $\lambda=532 \mathrm{~nm}$ and $\lambda=1064 \mathrm{~nm}$ (see Fig. 1-b). We observe a steep increase of $\mathrm{n}_{2}$ as the input central peak intensity $I_{0}$ increases. Then, after having reached a maximum value, $\mathrm{n}_{2}$ decreases rapidly again. We observed the same evolution for both wavelengths, except that, at $\lambda=1064 \mathrm{~nm}$, the variations are slower and the intensity range is wider. These results call into question the use of $\mathrm{CS}_{2}$ as a reference material for calibrating nonlinearities measurement systems since it is not a constant even in the weakly nonlinear regime. The definition of $\mathrm{n}_{4}$ is a fortiori problematic.
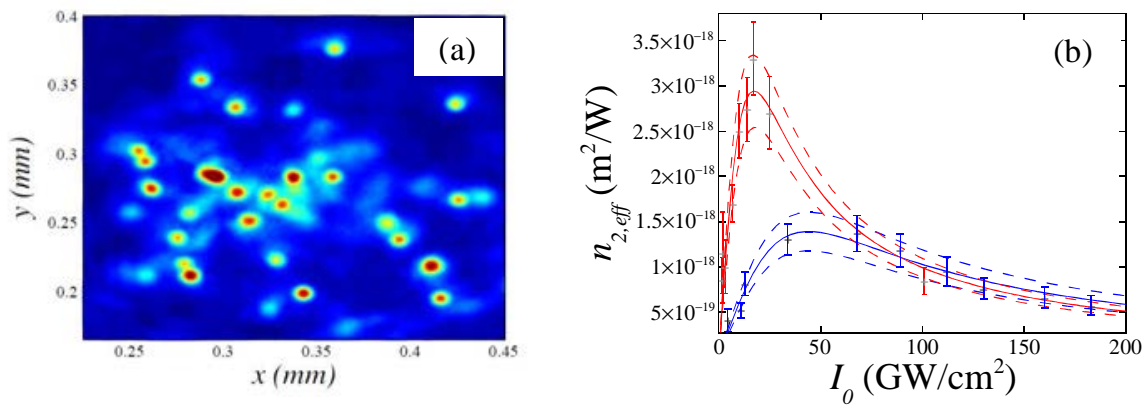

Fig. 1: (a) Filamentation observed at the output of the $\mathrm{CS}_{2}$ cell, for value of the pulse energy $14.2 \mu \mathrm{J}$, (b) $\mathrm{n}_{2, \text { eff }}$ versus $\mathrm{I}_{0}$ at $532 \mathrm{~nm}$ (solid red line) and at $1064 \mathrm{~nm}$ (solid blue line). The dashed lines correspond to fitting taking into account the uncertainties.

\section{Results and conclusions}

The measurements show that the usual formula $n_{2, \text { eff }}=n_{2}+n_{4} I$ cannot be used any more. The situation strongly differs from the experiments of [3] because the nonlinear index $n_{2, \text { eff }}$ is here increasing with moderate intensity instead of being decreasing. In other words, $\mathrm{n}_{4}$ is positive at the considered wavelengths, and not negative as in [3]. Indeed, measurements performed at moderate intensities have provided the values $\mathrm{n}_{4}=(1.2 \pm 0.3) \times 10^{-32} \mathrm{~m}^{4} / \mathrm{W}^{2}$ at $\lambda=532 \mathrm{~nm}, \mathrm{n}_{4}=(2.2 \pm 0.4) \times 10^{-33} \mathrm{~m}^{4} / \mathrm{W}^{2}$ at $\lambda=$ $1.064 \mu \mathrm{m}$ [8], in contrast with $\mathrm{n}_{4}=-2 \times 10^{-35} \mathrm{~m}^{4} / \mathrm{W}^{2}$ at $800 \mathrm{~nm}$ [10], or $\mathrm{n}_{4}=-5.2 \times 10^{-35} \mathrm{~m}^{4} / \mathrm{W}^{2}$ at $920 \mathrm{~nm}$ [3]. The change in the sign of $\mathrm{n}_{4}$ with wavelength is related to the location of the third harmonic with respect to the absorption bands of the material. The main point is that, in the present situation, the saturation of the Kerr effect cannot be accounted for by the $\mathrm{n}_{4}$ term. One may consider the option of retaining more terms in the expansion of the response function of the material in a power series of the electric field (higher order nonlinear susceptibilities). However, a difficulty would arise then. From theoretical point of view, the expansion cannot remain valid when the higher order corrections get the same order of magnitude as the leading one. In [3], it was possible to have the $n_{4}$ term comparable to the $n_{2}$ one, because the third harmonic resonance increased considerably the former with respect to the latter, which was not resonant. Hence we decided to provide an empirical model which describes the experimentally observed variations of $n_{2}$ with intensity, by fitting the experimental curve with an adequate Ansatz. After several trials, we found that $n_{2, e f f}(\mathrm{I})=\mathrm{aI} /\left(1+\mathrm{b}^{2} \mathrm{I}^{2}\right)$ allowed to correctly reproduce the data at $532 \mathrm{~nm}$ and $1064 \mathrm{~nm}$. The best fit, for data at $532 \mathrm{~nm}$, is obtained with the set of parameters $\mathrm{a}=3.4 \times 10^{-32} \mathrm{~m}^{4} / \mathrm{W}^{2}, \mathrm{~b}=5.8 \times 10^{-15} \mathrm{~m}^{2} / \mathrm{W}$; while at $1064 \mathrm{~nm}$, $\mathrm{a}=6.3 \times 10^{-33} \mathrm{~m}^{4} / \mathrm{W}^{2}$ and $\mathrm{b}=2.3 \times 10^{-15} \mathrm{~m}^{2} / \mathrm{W}$ as illustrated in Fig. 1-b. Numerical computations based on a NLS-type model using the above expression of the nonlinear index allowed to reproduce the experimental observations of the filamentation [4]. In conclusion accurate measurements of the nonlinear optical parameters have shown unexpected variations of the effective nonlinear index with intensity in $\mathrm{CS}_{2}$. The saturation of the Kerr effect, which is responsible for the formation of filaments, cannot be using the standard $\mathrm{n}_{2}-\mathrm{n}_{4}$ model leading to an alternative model in filamentation when combined to NLS equation.

\section{References}

1 V.I. Bespalov and V.I. Talanov, ZHETF Pis'ma 3 (11) 471-476 (1966).

2 A. Couairon, A. Mysyrowicz, «Femtosecond filamentation in transparent media », Physics Reports, 441, 47-189, (2007)

3 E. L. Falcão-Filho, C. B. de Araujo, G. Boudebs, H. Leblond and V. Skarka, Phys. Rev. Lett. 110, 013901, (2013)

4 V. Besse, H. Leblond, and G. Boudebs, "Filamentation of light in carbon disulfide", to be published, Phys. Rev. A., (2014)

5 M. Sheik-Bahae, A. A. Said, T. H. Wei, D. Hagan and E. W. Van Stryland, IEEE J. Quant. Electron. 26 (1990).

6 S. Cherukulappurath, J. L. Godet and G. Boudebs, J. Nonlinear Opt. Phys. Mater. 14, 1 (2005).

7 G. Boudebs, S. Cherukulappurath, H. Leblond, J. Troles, F. Smektala and F. Sanchez, Opt. Commun. 219 (2003)

8 V. Besse, G. Boudebs, H. Leblond, Appl. Phys. B., in press. DOI: 10.1007/s00340-014-5777-2, (2014)

9 G. Boudebs, V. Besse, C. Cassagne, H. Leblond and C. B. de Araujo, Opt. Lett. 38, 13 (2013).

10 D. G. Kong, Q. Chang, H. A. Ye, Y. C. Gao, Y. X. Wang, X. R. Zhang, K. Yang, W. Z. Wu and Y. L. Song, J. Phys. B: At. Mol. Opt. Phys. 42, 065401 (2009). 